\title{
Analysis of CAPZA3 localization reveals temporally discrete events during the acrosome reaction
}

\author{
Julian Sosnik ${ }^{1}$, Mariano Buffone ${ }^{2}$, and Pablo E. Visconti ${ }^{1,{ }^{*}}$ \\ ${ }^{1}$ Department of Veterinary \& Animal Sciences and Molecular and Cellular Biology, Graduate \\ Program, University of Massachusetts, Amherst, MA, US. \\ ${ }^{2}$ Instituto de Biologia y Medicina Experimental, CONICET, Buenos Aires, Argentina.
}

\begin{abstract}
In mammals, the starting point of development is the fusion between sperm and egg. It is well established that sperm fuse with the egg through the equatorial/postacrosomal region. Apart from this observation and the requirement of two proteins (CD9 in the egg and IZUMO1 in the sperm) very little is known about this fundamental process. actin polymerization correlates with sperm capacitation in different mammalian species and it has been proposed that F-actin breakdown is needed during the acrosome reaction. Recently, we have presented evidence that actin polymerization inhibitors block the movement of IZUMO1 that accompany the acrosome reaction. These results suggest that actin dynamics play a role in the observed changes in IZUMO1 localization. This finding is significant because IZUMO1 localization in acrosome-intact sperm is not compatible with the known location of the initiation of the fusion between the sperm and the egg. To further understand the actin-mediated changes in protein localization during the acrosome reaction, the distribution of the sperm-specific plus-end actin capping protein CAPZA3 was analyzed. Like IZUMO1, CAPZA3 shows a dynamic pattern of localization; however, these movements follow a different temporal pattern than the changes observed with IZUMO1. In addition, the actin polymerization inhibitor latrunculin A was unable to alter CAPZA3 movement.
\end{abstract}

\section{Keywords}

CAPZA3; actin; sperm; capacitation; acrosome reaction

\section{Introduction}

The actin cytoskeleton is required for intracellular protein transport and appears to have an essential role in the secretory pathway (Hirschberg et al., 1998; Valderrama et al., 2001). In sperm, the role of actin polymerization in capacitation and the acrosome reaction has been the focus of numerous studies. More specifically, experiments using phalloidin staining have shown that actin polymerization correlates with sperm capacitation in different mammalian species (Brener et al., 2003; Cabello-Agueros et al., 2003; Castellani-Ceresa et al., 1993; Dvorakova et al., 2005). It has also been proposed that F-actin breakdown occurs during the

${ }^{*}$ Correspondence to: Pablo E. Visconti, Department of Veterinary and Animal Sciences, University of Massachusetts, Amherst, 208 Paige Laboratories, Amherst, MA 01003, USA, Tel: (413) 545-5565, FAX: (413) 545-6326, pvisconti@ vasci.umass.edu. 
acrosome reaction (Brener et al., 2003). Consistent with the idea that actin dynamics play a role in sperm function, inhibitors of actin polymerization in human sperm inhibited the acrosome reaction (Liu et al., 1999; Liu et al., 2002) and prevented fusion with zona-free hamster eggs (Rogers et al., 1989). Interestingly, several actin-binding proteins, some of which are testis-specific, have been shown to be present in mammalian sperm. Examples of this are: CALICIN (von Bulow et al., 1995), the capping proteins CP $\beta 3$ (von Bulow et al., 1997), SCINDERIN (Pelletier et al., 1999), DESTRIN, THYMOSIN $\beta 10$, testis-specific actin capping protein (Howes et al., 2001), the actin-related proteins ARP-T1 and T2 (Heid et al., 2002) and Arc (Maier et al., 2003).

In addition to the proposed role in the acrosome reaction, actin polymerization and depolymerization have been implicated in the well-established changes in the immunofluorescence pattern of sperm proteins that occur during capacitation and the acrosome reaction (Hernandez-Gonzalez et al., 2000; Saxena et al., 1986). One of the proteins that change localization during the acrosome reaction is IZUMO1 (Inoue et al., 2005; Kawai et al., 1989; Miranda et al., 2009; Okabe et al., 1987; Sosnik et al., 2009). Using a knock-out approach, Inoue et al. (Inoue et al., 2005) demonstrated that IZUMO1 is required for sperm-egg fusion. However, before the acrosome reaction, IZUMO1 localization is restricted to the dorsal portion of the sperm anterior head, a region that does not appear to be involved in fusion with the egg (Yanagimachi, 1994). Interestingly, after the acrosome reaction, IZUMO1 redistributes to other sperm compartments including the post-acrosome and other regions, which are compatible with the role of IZUMO1 in spermegg fusion. IZUMO1 is a member of a multi-protein family that forms complexes and is the only member of the family known to present this relocalization (Ellerman et al., 2009). Recently, our group reported that mice lacking the testis-specific serine kinase 6 (TSSK6) are also incapable to fuse with the egg (Sosnik et al., 2009). IZUMO1 is present in Tssk6null sperm; however, this protein remains in the anterior head and does not redistribute following the acrosome reaction. Furthermore, IZUMO1 redistribution during the acrosome reaction is blocked by latrunculin A, an inhibitor of actin polymerization; by ML7 an inhibitor of myosin light chain kinase and by Blebbistatin, a MYOSIN II inhibitor. Altogether, these observations support the hypothesis that actin polymerization and depolymerization play a role in IZUMO1 movements and that this change in localization is needed for the role of this protein in gamete fusion.

In the present study, the movement of IZUMO1 was compared with changes in the localization of CAPZA3, a testis-specific actin-capping protein. CAPZA3 plays a role in maintaining polymerized actin during spermiogenesis (Geyer et al., 2009). Evidence provided here indicates that, similar to IZUMO1, CAPZA3 localized to the anterior head in intact sperm. When IZUMO1 starts to move during the initial steps of the acrosome reaction, CAPZA3 has already redistributed to the posterior acrosome. At the end of the process, when the acrosome is no longer present and IZUMO1 is detected in the posterior acrosome, no more staining of CAPZA3 in the head is observed. Contrary to IZUMO1 movement and consistent with a role in stabilization of polymerized actin, CAPZA3 relocalization and posterior loss is not affected in the presence of latrunculin A. 


\section{Reagents, Antibodies and Media}

All media and reagents were purchased from Sigma-Aldrich (St. Louis, MO) unless specified otherwise. Antibody against CAPZa 3 was purchased from American Research Products, Inc. (Belmont, MA). Antibodies against IZUMO1 were donated by Dr. Masaru Okabe (Inoue et al., 2005). Secondary antibodies, PNA conjugated to Alexa fluorophores and DAPI were obtained from Molecular Probes (Eugene, OR). Secondary antibodies conjugated to horseradish peroxidase were purchased from Jackson Immunoresearch Laboratories (West Grove, PA). Calcium ionophore A23187 and latrunculin A were obtained from Calbiochem (San Diego, CA).

\section{Animal Care and Use}

Procedures involving animal experimentation were conducted according to animal research protocols approved by the Institutional Animal Care and Use Committee, University of Massachusetts, Amherst. CD1 retired breeder male mice were acquired from Charles River Laboratory, housed and handled according to the aforementioned protocols.

\section{Sperm Sample Preparation}

Sperm samples were obtained in HEPES buffered Whitten medium without BSA or $\mathrm{NaHCO}_{3}$ (Whitten and Biggers, 1968) at $37^{\circ} \mathrm{C}$ from epididymal cauda of CD1 retired breeder male mice. The caudæ were snipped and kept in medium at $37^{\circ} \mathrm{C}$ for 7 minutes to allow the sperm to "swim-out". Sperm were rinsed once before further treatment (Hernandez-Gonzalez et al., 2006).

For the analysis of CAPZA3 localization, sperm were incubated in HEPES buffered Whitten medium without (non-capacitated) or with (capacitated) $5 \mathrm{mg} / \mathrm{ml}$ of BSA and $10 \mathrm{mM}$ $\mathrm{NaHCO}_{3}$ for 60 minutes at $37^{\circ} \mathrm{C}$. The acrosome reaction was then induced with $10 \mu \mathrm{M} \mathrm{Ca}^{2+}$ ionophore $\mathrm{A} 23187$ for 30 minutes at $37^{\circ} \mathrm{C}$. The capacitated and non-capacitated sperm were incubated for an additional 30 minutes at $37^{\circ} \mathrm{C}$ without any additions. When latrunculin A was used, the inhibitor was included in the media from the beginning of the incubation at a final concentration of $25 \mu \mathrm{M}$ (Boyle et al., 2001; Sosnik et al., 2009).

\section{Immunocytochemistry}

Samples were treated as described previously (Sosnik et al., 2009). Briefly, after swim-out, sperm cells were spotted onto coverslips and allowed to adhere at room temperature for 10 minutes. After fixation, cells were permeabilized with $0.5 \%$ Triton-X100 in PBS at room temperature for 5 minutes, and non-specific binding blocked with PBS containing $0.1 \%$ Tween-20 and $0.5 \%$ BSA. Incubation with corresponding primary antibodies (at 1:100 dilutions from the original concentrations in blocking buffer) was carried out overnight at $4^{\circ} \mathrm{C}$. After washings, cells were incubated with the appropriate secondary antibodies and desired counterstains diluted in blocking solution at room temperature for no less than 2 hours. Finally the coverslips were washed 10 times at room temperature in PBS- $0.1 \%$ Tween-20, mounted on slides with SlowFade ${ }^{\circledR}$ Light (Molecular Probes, Eugene, OR) mounting media, and left at $4^{\circ} \mathrm{C}$ until imaged. Imaging was performed with a Nikon Eclipse 200 inverted microscope equipped with Differential Interference Contrast optics, epifluorescence, a CCD camera and Open Lab imaging software. 


\section{Western Blots}

Protein analysis by SDS-PAGE was performed as previously described (Jha et al., 2007). Protein extracts from cauda epididymal sperm were obtained in non-reducing Laemmli buffer (Laemmli, 1970) and boiled for 5 minutes. The samples were then centrifuged at $10^{4}$ $G$ for 5 minutes and the supernatant was reduced for 2 minutes at $95^{\circ} \mathrm{C}$ with $5 \% \beta$ Mercapto-Ethanol. Five million sperm were loaded into $10 \%$ acrylamide gels and separated by SDS-PAGE. Proteins were then transferred to PVDF membranes and specific signals detected with anti-CAPZA3 antibody (at 1:1000 dilution from the original concentration in PBS-0.1\% Tween-20) followed by HRP conjugated goat anti-guinea pig antibody for secondary detection by chemiluminescence.

\section{RESULTS}

\section{CAPZA3 redistributed during capacitation and the acrosome reaction}

CAPZA3 is an actin-capping protein believed to be involved in the control of actin polymerization during spermiogenesis (Geyer et al., 2009) and has also been shown to be present in mature sperm (Tokuhiro et al., 2008). Because of findings suggesting that the actin cytoskeleton was involved in IZUMO1 movement, the localization of CAPZA3 was investigated in sperm populations incubated under different conditions. These experiments were conducted using a polyclonal antibody against a specific peptide from CAPZA3 (GPSH4). This antibody is commercially available and recognized a single band of $31 \mathrm{kDa}$ in sperm extracts (Fig. S1-A). Immunofluorescence experiments showed that CAPZA3 localized to the anterior head (Fig. 1, left panel). To study whether CAPZA3 also undergoes changes in localization during capacitation or the acrosome reaction, cauda-epididymal sperm from mature CD1 male mice were incubated in three different conditions. One set of sperm was incubated in media lacking bovine serum ALBUMIN (BSA) or $\mathrm{NaHCO}_{3}$ (NonCap) which does not support capacitation. A second group was incubated for 90 minutes at $37^{\circ} \mathrm{C}$ in medium containing BSA and $\mathrm{NaHCO}_{3}$ that supports capacitation (Cap). The third sperm aliquot was incubated for 60 minutes in capacitating media and then $5 \mu \mathrm{M} \mathrm{Ca}^{2+}$ ionophore A23187 was added for an additional $30 \mathrm{~min}$. to induce the acrosome reaction (AR).

After treatment all sperm were fixed and immunostained for microscopic analysis of CAPZA3 localization. In order to assess the acrosomal status of the fixed and permeabilized sperm, Alexa Fluor ${ }^{\circledR} 568$ labeled peanut lectin PNA was used as a counterstain (Fig. 1).

Although with some variation in the intensity level, all sperm showed CAPZA3 staining in the flagellum midpiece. In addition we observed four different patterns of staining in the sperm head that included staining in the anterior head, a diffuse staining of the whole head, a post-acrosomal staining and also sperm with undetectable staining. When the different CAPZA3 staining patterns were correlated with the respective PNA staining, it was possible to identify a very significant correlation between the localization of CAPZA3 and the status of the sperm acrosome. While most of the sperm incubated under non-capacitating conditions presented an anterior head staining (Fig. 1 and Table 1, Non Cap), most of the capacitated sperm population displayed a diffuse staining pattern (Fig. 1 and Table 1, Cap). 
On the other hand, calcium ionophore-treated, acrosome-reacted sperm showed only two different patterns of staining; one of them was a clear post-acrosomal localization, the other one was complete lack of staining (Fig. 1 and Table 1). Close examination of the PNA staining in these two populations indicated that those sperm depicting post-acrosomal staining still had some level of PNA staining suggesting that the acrosomal exocytosis was not complete. Based on these differences, we classified sperm as 'initial acrosome reacted' sperm or $\mathrm{AR}_{\mathrm{i}}$, without complete loss of PNA staining. In contrast, those with complete loss of PNA staining were considered in a final stage of the acrosome reaction $\left(\mathrm{AR}_{\mathrm{f}}\right)$. Interestingly, using this classification, a strong correlation between CAPZA3 staining and acrosomal status was observed. While $95 \%$ of $\mathrm{AR}_{\mathrm{i}}$ sperm presented post-acrosomal staining for CAPZA3, $91 \%$ of $\mathrm{AR}_{\mathrm{f}}$ sperm have undetectable levels of CAPZA3 staining (Fig. 1 \& Table 1).

\section{CAPZA3 movement precedes relocalization of IZUMO1}

IZUMO1 relocalization from the anterior head to the posterior equatorial segment/postacrosomal compartment is inhibited by latrunculin A and myosin dynamic inhibitors, suggesting that this movement is dependent on the actin cytoskeleton (Sosnik et al., 2009). Because CAPZA3 is a plus-end, actin-capping protein, the possibility that the observed Capza3 changes in localization were coupled to IZUMO1 movement was analyzed. For this purpose, similar treatments to the ones described above were used. In this case, parallel immunostaining of CAPZA3 and IZUMO1 was conducted (Fig. 2). Acrosomal status was judged by the extent of IZUMO1 relocalization. Some sperm presented an enlarged anterior head staining of IZUMO1; following the previous classification, these sperm were categorized as $\mathrm{AR}_{\mathrm{i}}$. A second group of sperm presented a clear posterior pattern of IZUMO1 localization correlated with complete loss of PNA staining (Sosnik et al., 2009). These sperm were considered in the final stages of the acrosome reaction and were classified as $\mathrm{AR}_{\mathrm{f}}$. Using this categorization, CAPZA3 post-acrosomal staining is also correlated with the $\mathrm{AR}_{\mathrm{i}}$ sperm population and lack of CAPZA3 staining correspond to the $\mathrm{AR}_{\mathrm{f}}$ sperm population (Table 2). These experiments suggest that CAPZA3 relocalization precedes the movement of IZUMO1.

Considering that reagents that affect the actin cytoskeleton inhibit IZUMO1 movement, it is possible that CAPZA3 movement is also dependent on actin dynamics. To investigate this possibility, the actin polymerization inhibitor toxin latrunculin A was used (Table 3). Latrunculin A acts by binding monomeric actin units thus preventing them from forming filaments (Spector et al., 1989). As shown in Table 3, no differences in the CAPZA3 localization pattern were observed in control experiments were cauda sperm was incubated in the presence of $10 \mu \mathrm{M}$ latrunculin A under the same conditions described above.

\section{DISCUSSION}

The extent of actin polymerization is regulated by a dynamic equilibrium between monomeric and filamentous actin. In most cells, particularly in the transcriptionally and translationally inactive mature sperm, the amount of total actin does not change considerably. This fact underscores the role of actin binding proteins to promote, stabilize or 
prevent the formation of thin filaments and control actin dynamics. Among these proteins, CAPZ is an actin capping protein involved in the regulation of actin assembly at the plus end of filaments. In testicular postmeiotic germ cells, there are two unique members of the CAPZ protein family, CAPZA3 and CAPZB3. While Capza3 is an independent intronless gene, CAPZB3 differs from the other CAPZB by a unique $\mathrm{N}$-terminus produced by alternative splicing. Repro32 is a mouse strain produced as part of the Reproductive Genomics program at The Jackson Laboratory (http://reproductivegenomics.jax.org/) using random Nethyl-N-nitrosourea (ENU) mutagenesis and has been shown to present a male sterility phenotype (Handel et al., 2006; Lessard et al., 2007). Sterility of the repro32/ repro32 mouse is due to a missense mutation in the Capza3 gene (Geyer et al., 2009). Moreover, this work presents strong evidence that lack of CAPZA3 disrupts the filamentous actin network and consequently repro32/repro32 mice present defects in the removal of cytoplasm and in the maintenance of midpiece integrity that is observed during spermiogenesis. In addition, phenotypic studies indicate that sperm from the repro32 heterozygous mice have low cauda epididymal sperm numbers, poor sperm motility, and abnormal sperm morphology (Geyer et al., 2009). In addition to this work, a recent report shows that CAPZA3, also known as CPa3, is present in mature sperm (Tokuhiro et al., 2008).

Besides its role in spermiogenesis, the presence of CAPZA3 in mature sperm is consistent with the proposed role of actin polymerization in capacitation and the acrosome reaction (Brener et al., 2003; Dvorakova et al., 2005; Etkovitz et al., 2007; Hernandez-Gonzalez et al., 2000; Rogers et al., 1989; Sosnik et al., 2009). In mammals, one of the current hypothesis states that actin polymerization is part of the capacitation process and it is downstream of signaling cascades involving cAMP (Breitbart et al., 2005). Using phalloidin staining, several groups have shown the presence of F-actin in the anterior acrosome as well as in the post-acrosomal region (Brener et al., 2003; Delgado-Buenrostro et al., 2005; Liu et al., 1999). This staining is significantly reduced in acrosome-reacted sperm, suggesting that depolymerization of actin is concomitant to exocytosis (Brener et al., 2003; Liu et al., 1999). Consistent with a role of actin in the acrosome reaction, inhibitors of actin polymerization such as latrunculin A or cytochalasin D are able to block the acrosome reaction (Brener et al., 2003).

As other CAPZ proteins, CAPZA3 is predicted to play a role in the regulation of actin dynamics. In addition to exocytosis, the acrosome reaction exposes proteins needed for sperm-egg fusion. Among the proteins proposed to reorganize following the acrosome reaction, only IZUMO1 has been shown to play a necessary role in this process using a knockout approach. Because the sperm fusion to the egg occurs from a postacrosomal/ equatorial region, the IZUMO1 anterior acrosome localization in acrosome intact sperm is not compatible with the proposed role of this protein in gamete fusion. Interestingly, IZUMO1 changes its localization during the acrosome reaction (Inoue et al., 2005; Kawai et al., 1989; Miranda et al., 2009; Okabe et al., 1987; Sosnik et al., 2009).

The present work focused on the distribution of CAPZA3 in mature mouse sperm. Similar to the dynamic changes in the localization of other actin binding proteins in guinea pig sperm (Delgado-Buenrostro et al., 2005), CAPZA3 redistributed during capacitation and the 
acrosome reaction. Initially, CAPZA3 localized to the anterior acrosome and remained there when sperm were incubated in the absence of BSA and $\mathrm{HCO}_{3^{-}}$, conditions that do not support capacitation. When mouse sperm were incubated in conditions that support capacitation, CAPZA3 presented a more diffuse staining pattern throughout the whole sperm head. Both, the staining pattern restricted to the acrosome as well as the diffuse patterns were observed in intact sperm as indicated by the presence of PNA staining and by the localization of IZUMO1 in the anterior acrosome. Shortly after the induction of the acrosome reaction, CAPZA3 redistributed to the post-acrosomal compartment; this fluorescent pattern correlated with a lighter and more punctuated PNA staining and with a larger area of IZUMO1 staining. These data suggest that CAPZA3 postacrosomal localization corresponded to initial stages of the acrosome reaction. Finally, in sperm presenting complete loss of PNA staining in the acrosome as well as IZUMO1 localization in the post-acrosomal region, CAPZA3 signal was undetectable. It is important to note that although the present work strongly suggests that CAPZA3 relocates posteriorly in the mouse sperm head, the data here presented cannot rule out the possibility of changes in epitope accessibility. CAPZA3 staining in the mid-piece was observed in sperm incubated in all conditions.

As mentioned, CAPZA3 is completely relocated to the post-acrosomal region when IZUMO1 has only started to redistribute, suggesting that the redistribution of these two proteins might occur through different mechanisms. On the other hand, the lack of CAPZA3 staining in sperm that have completed the acrosome reaction could be explained either by loss of CAPZA3 or alternatively, this result could also mean that the CAPZA3 antigenic site is not available to anti-CAPZA3 antibodies in these conditions. In addition, contrary to IZUMO1, inhibition of actin polymerization with latrunculin A did not affect CAPZA3 redistribution. Because of the presence of actin related proteins in the mouse sperm head and the unknown effects of latrunculin A in such proteins, it is possible that CAPZA3 relocalization occurs by means of actin related proteins. Alternatively, CAPZA3 relocalization could be regulated by changes in anchoring proteins, being the movement due to intracellular diffusion. Taking into consideration the predicted role of CAPZA3 as an actin capping protein, our observations are consistent with a model in which CAPZA3 redistributes upon sperm capacitation, anchoring in the post-acrosomal compartment upon acrosome reaction. In this new location, CAPZA 3 could play a role in the stabilization of polymerized actin and a subsequent myosin-dependent movement of IZUMO1 to the fusogenic site using the actin cytoskeleton. Most cells control the length of actin filaments under conditions that maintain total actin concentration. Proteins that cap or prevent the dynamic exchange of actin monomers play an important role in the regulation of actin polymerization (C. G. DOS REMEDIOS, D. CHHABRA, M. KEKIC, I. V. DEDOVA, M. TSUBAKIHARA, D. A. BERRY, AND N. J. NOSWORTHY, Physiol. Rev. 2003). In somatic cells, the capping of filaments is regulated by second messengers such as PIP and PIP2. The finding that Capza 3 change localization in the early steps of the acrosome reaction suggests that similar to the somatic counterparts, Capza 3 function is regulated by second messengers. Interestingly, it has been shown that phospholipid metabolism is activated during the acrosome reaction (Jungnickel, Sutton and Florman, Dev. Biol. 2007). Although unique to the sperm, the acrosome reaction shares many of the same properties as 
other exocytotic processes; therefore, observations in this manuscript might be relevant to the study of other CapZ capping proteins and actin polymerization in other systems.

\section{Supplementary Material}

Refer to Web version on PubMed Central for supplementary material.

\section{Acknowledgments}

This work was supported by the following grants:

Contract grant sponsor: NIH; Contract grant numbers: NIH HD038082 and NIH HD044044 (to PEV) and NIH F31HD049324 (to JS).

We would like to thank Dr. Masaru Okabe (Osaka University, Japan) for his generous contribution of anti-IZUMO1 antibodies. We would also like to thank Dr. Alfandari and Dr. Salicioni (University of Massachusetts, Amherst) for their input.

\section{Literature Cited}

Boyle JA, Chen H, Bamburg JR. Sperm incorporation in Xenopus laevis: characterisation of morphological events and the role of microfilaments. Zygote. 2001; 9(2):167-181. [PubMed: 11358324]

Bradford MM. A rapid and sensitive method for the quantitation of microgram quantities of protein utilizing the principle of protein-dye binding. Anal Biochem. 1976; 72:248-254. [PubMed: 942051]

Breitbart H, Cohen G, Rubinstein S. Role of actin cytoskeleton in mammalian sperm capacitation and the acrosome reaction. Reproduction. 2005; 129(3):263-268. [PubMed: 15749953]

Brener E, Rubinstein S, Cohen G, Shternall K, Rivlin J, Breitbart H. Remodeling of the actin cytoskeleton during mammalian sperm capacitation and acrosome reaction. Biol Reprod. 2003; 68(3):837-845. [PubMed: 12604633]

Cabello-Agueros JF, Hernandez-Gonzalez EO, Mujica A. The role of F-actin cytoskeleton-associated gelsolin in the guinea pig capacitation and acrosome reaction. Cell Motil Cytoskeleton. 2003; 56(2): 94-108. [PubMed: 14506707]

Castellani-Ceresa L, Mattioli M, Radaelli G, Barboni B, Brivio MF. Actin polymerization in boar spermatozoa: fertilization is reduced with use of cytochalasin D. Mol Reprod Dev. 1993; 36(2): 203-211. [PubMed: 8257569]

Delgado-Buenrostro NL, Hernandez-Gonzalez EO, Segura-Nieto M, Mujica A. Actin polymerization in the equatorial and postacrosomal regions of guinea pig spermatozoa during the acrosome reaction is regulated by G proteins. Mol Reprod Dev. 2005; 70(2):198-210. [PubMed: 15570614]

Dvorakova K, Moore HD, Sebkova N, Palecek J. Cytoskeleton localization in the sperm head prior to fertilization. Reproduction. 2005; 130(1):61-69. [PubMed: 15985632]

Ellerman DA, Pei J, Gupta S, Snell WJ, Myles D, Primakoff P. Izumo is part of a multiprotein family whose members form large complexes on mammalian sperm. Mol Reprod Dev. 2009; 76(12):11881199. [PubMed: 19658160]

Etkovitz N, Rubinstein S, Daniel L, Breitbart H. Role of PI3-kinase and PI4-kinase in actin polymerization during bovine sperm capacitation. Biol Reprod. 2007; 77(2):263-273. [PubMed: 17494916]

Geyer CB, Inselman AL, Sunman JA, Bornstein S, Handel MA, Eddy EM. A missense mutation in the Capza3 gene and disruption of F-actin organization in spermatids of repro32 infertile male mice. Dev Biol. 2009; 330(1):142-152. [PubMed: 19341723]

Handel MA, Lessard C, Reinholdt L, Schimenti J, Eppig JJ. Mutagenesis as an unbiased approach to identify novel contraceptive targets. Mol Cell Endocrinol. 2006; 250(1-2):201-205. [PubMed: 16412559] 
Hao Z, Jha KN, Kim YH, Vemuganti S, Westbrook VA, Chertihin O, Markgraf K, Flickinger CJ, Coppola M, Herr JC, Visconti PE. Expression analysis of the human testis-specific serine/ threonine kinase (TSSK) homologues. A TSSK member is present in the equatorial segment of human sperm. Mol Hum Reprod. 2004; 10(6):433-444. [PubMed: 15044604]

Heid H, Figge U, Winter S, Kuhn C, Zimbelmann R, Franke W. Novel actin-related proteins Arp-T1 and Arp-T2 as components of the cytoskeletal calyx of the mammalian sperm head. Exp Cell Res. 2002; 279(2):177-187. [PubMed: 12243744]

Hernandez-Gonzalez EO, Lecona-Valera AN, Escobar-Herrera J, Mujica A. Involvement of an F-actin skeleton on the acrosome reaction in guinea pig spermatozoa. Cell Motil Cytoskeleton. 2000; 46(1):43-58. [PubMed: 10842332]

Hernandez-Gonzalez EO, Sosnik J, Edwards J, Acevedo JJ, Mendoza-Lujambio I, Lopez-Gonzalez I, Demarco I, Wertheimer E, Darszon A, Visconti PE. Sodium and epithelial sodium channels participate in the regulation of the capacitation-associated hyperpolarization in mouse sperm. $\mathrm{J}$ Biol Chem. 2006; 281(9):5623-5633. [PubMed: 16407190]

Hirschberg K, Miller CM, Ellenberg J, Presley JF, Siggia ED, Phair RD, Lippincott-Schwartz J. Kinetic analysis of secretory protein traffic and characterization of golgi to plasma membrane transport intermediates in living cells. J Cell Biol. 1998; 143(6):1485-1503. [PubMed: 9852146]

Howes EA, Hurst SM, Jones R. Actin and actin-binding proteins in bovine spermatozoa: potential role in membrane remodeling and intracellular signaling during epididymal maturation and the acrosome reaction. J Androl. 2001; 22(1):62-72. [PubMed: 11191089]

Inoue $\mathrm{N}$, Ikawa $\mathrm{M}$, Isotani A, Okabe $\mathrm{M}$. The immunoglobulin superfamily protein Izumo is required for sperm to fuse with eggs. Nature. 2005; 434(7030):234-238. [PubMed: 15759005]

Jha KN, Salicioni AM, Arcelay E, Chertihin O, Kumari S, Herr JC, Visconti PE. Evidence for the involvement of proline-directed serine/threonine phosphorylation in sperm capacitation. Mol Hum Reprod. 2006; 12(12):781-789. [PubMed: 17050774]

Kawai Y, Hama T, Mayumi T, Okabe M, Matzno S, Kohama Y, Mimura T. Flow cytometric analysis of mouse sperm using monoclonal anti-sperm antibody OBF13. J Reprod Immunol. 1989; 16(1): 71-82. [PubMed: 2513398]

Laemmli UK. Cleavage of structural proteins during the assembly of the head of bacteriophage T4. Nature. 1970; 227(5259):680-685. [PubMed: 5432063]

Lessard C, Lothrop H, Schimenti JC, Handel MA. Mutagenesis-generated mouse models of human infertility with abnormal sperm. Hum Reprod. 2007; 22(1):159-166. [PubMed: 16920728]

Liu DY, Martic M, Clarke GN, Dunlop ME, Baker HW. An important role of actin polymerization in the human zona pellucida-induced acrosome reaction. Mol Hum Reprod. 1999; 5(10):941-949. [PubMed: 10508222]

Liu DY, Martic M, Clarke GN, Grkovic I, Garrett C, Dunlop ME, Baker HW. An anti-actin monoclonal antibody inhibits the zona pellucida-induced acrosome reaction and hyperactivated motility of human sperm. Mol Hum Reprod. 2002; 8(1):37-47. [PubMed: 11756568]

Maier B, Medrano S, Sleight SB, Visconti PE, Scrable H. Developmental association of the synaptic activity-regulated protein arc with the mouse acrosomal organelle and the sperm tail. Biol Reprod. 2003; 68(1):67-76. [PubMed: 12493697]

Marks JA, Biermann CH, Eanes WF, Kryvi H. Sperm polymorphism within the sea urchin Strongylocentrotus droebachiensis: divergence between Pacific and Atlantic oceans. Biol Bull. 2008; 215(2):115-125. [PubMed: 18840772]

Miranda PV, Allaire A, Sosnik J, Visconti PE. Localization of Low-Density Detergent-Resistant Membrane Proteins in Intact and Acrosome-Reacted Mouse Sperm. Biol Reprod. 2009; 80(5): 897-904. [PubMed: 19144954]

North AJ. Seeing is believing? A beginners' guide to practical pitfalls in image acquisition. J Cell Biol. 2006; 172(1):9-18. [PubMed: 16390995]

Okabe M, Adachi T, Takada K, Oda H, Yagasaki M, Kohama Y, Mimura T. Capacitation-related changes in antigen distribution on mouse sperm heads and its relation to fertilization rate in vitro. $\mathrm{J}$ Reprod Immunol. 1987; 11(2):91-100. [PubMed: 3625612] 
Pelletier R, Trifaro JM, Carbajal ME, Okawara Y, Vitale ML. Calcium-dependent actin filamentsevering protein scinderin levels and localization in bovine testis, epididymis, and spermatozoa. Biol Reprod. 1999; 60(5):1128-1136. [PubMed: 10208974]

Rogers BJ, Bastias C, Coulson RL, Russell LD. Cytochalasin D inhibits penetration of hamster eggs by guinea pig and human spermatozoa. J Androl. 1989; 10(4):275-282. [PubMed: 2777719]

Saxena N, Peterson RN, Sharif S, Saxena NK, Russell LD. Changes in the organization of surface antigens during in-vitro capacitation of boar spermatozoa as detected by monoclonal antibodies. $\mathrm{J}$ Reprod Fertil. 1986; 78(2):601-614. [PubMed: 3806519]

Sosnik J, Miranda PV, Spiridonov NA, Yoon SY, Fissore RA, Johnson GR, Visconti PE. Tssk6 is required for Izumo relocalization and gamete fusion in the mouse. J Cell Sci. 2009; 122(Pt 15): 2741-2749. [PubMed: 19596796]

Spector I, Shochet NR, Blasberger D, Kashman Y. Latrunculins--novel marine macrolides that disrupt microfilament organization and affect cell growth: I. Comparison with cytochalasin D. Cell Motil Cytoskeleton. 1989; 13(3):127-144. [PubMed: 2776221]

Spiridonov NA, Wong L, Zerfas PM, Starost MF, Pack SD, Paweletz CP, Johnson GR. Identification and characterization of SSTK, a serine/threonine protein kinase essential for male fertility. Mol Cell Biol. 2005; 25(10):4250-4261. [PubMed: 15870294]

Tokuhiro K, Miyagawa Y, Tanaka H. Characterizing mouse male germ cell-specific actin capping protein alpha3 (CPalpha3): dynamic patterns of expression in testicular and epididymal sperm. Asian J Androl. 2008; 10(5):711-718. [PubMed: 18645673]

Valderrama F, Duran JM, Babia T, Barth H, Renau-Piqueras J, Egea G. Actin microfilaments facilitate the retrograde transport from the Golgi complex to the endoplasmic reticulum in mammalian cells. Traffic. 2001; 2(10):717-726. [PubMed: 11576448]

von Bulow M, Heid H, Hess H, Franke WW. Molecular nature of calicin, a major basic protein of the mammalian sperm head cytoskeleton. Exp Cell Res. 1995; 219(2):407-413. [PubMed: 7641791]

von Bulow M, Rackwitz HR, Zimbelmann R, Franke WW. CP beta3, a novel isoform of an actinbinding protein, is a component of the cytoskeletal calyx of the mammalian sperm head. Exp Cell Res. 1997; 233(1):216-224. [PubMed: 9184090]

Whitten WK, Biggers JD. Complete development in vitro of the pre-implantation stages of the mouse in a simple chemically defined medium. J Reprod Fertil. 1968; 17(2):399-401. [PubMed: 5749384]

Yanagimachi R. Fertility of mammalian spermatozoa: its development and relativity. Zygote. 1994; 2(4):371-372. [PubMed: 8665172] 


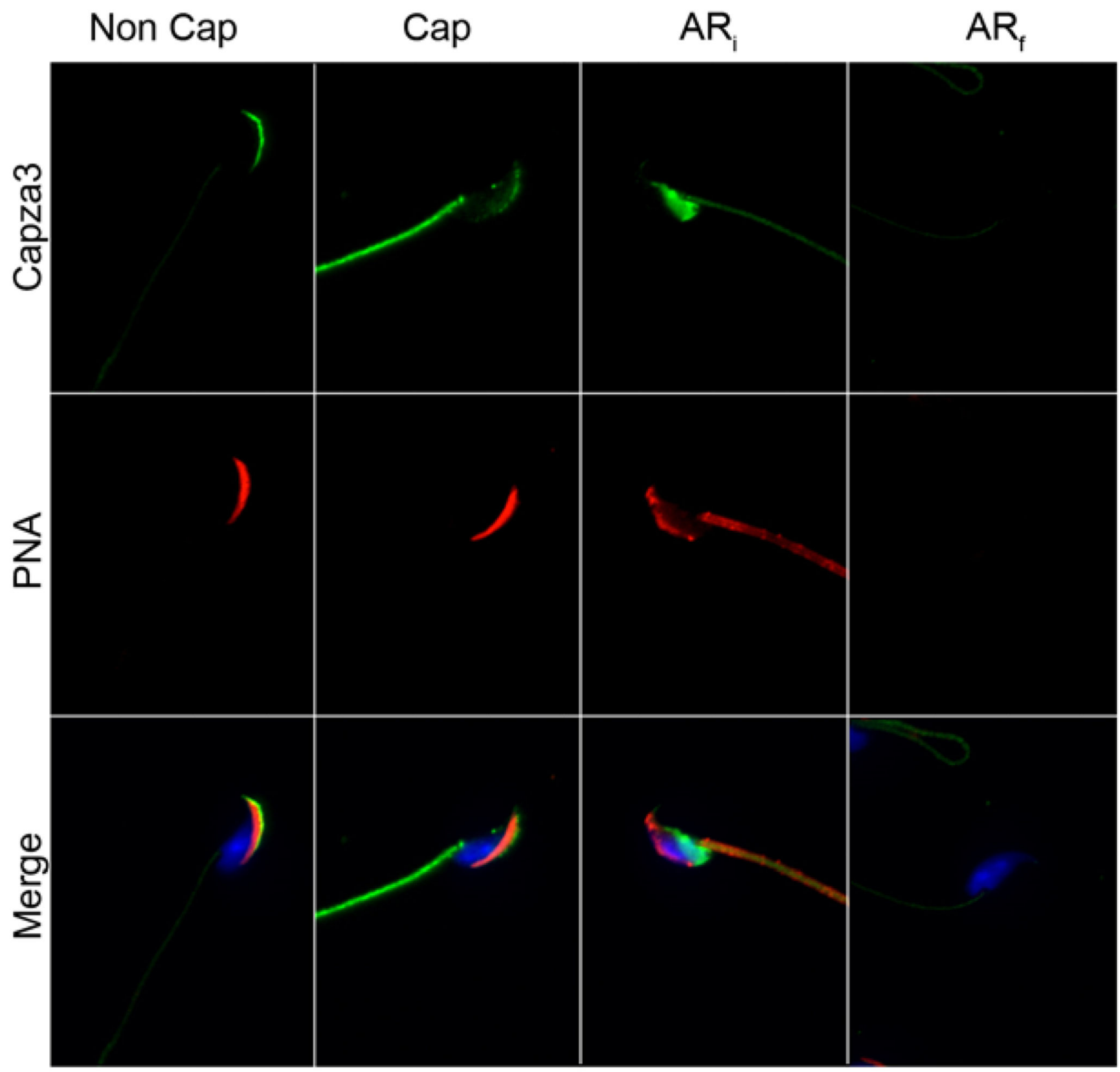

\section{Capza3 Localization}

Fig. 1. Capza3 presents a varied pattern of localization in mature mouse sperm Sperm from the cauda of the epididymis from mature mice were obtained and incubated in media lacking (Non Cap) or containing (Cap) albumin and $\mathrm{NaCHO}_{3}$ for 90 minutes at $37^{\circ} \mathrm{C}$. A third group was incubated in capacitating media for 60 minutes and an additional 30 minutes after the addition of $\mathrm{Ca}^{2+}$ ionophore (AR). The samples were then mounted on drops on glass slides and fixed as indicated in materials and methods. After permeabilization the samples were stained for Capza3 using the GP-SH4 antibody. Fluorescent secondary antibody was used in conjunction with fluorescent PNA and DAPI as counterstains. The 
extent of the acrosome reaction was judged by the extent of loss of PNA staining and samples separated for quantification into initial acrosome reaction $\left(\mathrm{AR}_{\mathrm{i}}\right)$ (samples retaining partial PNA staining) and final acrosome reaction $\left(\mathrm{AR}_{\mathrm{f}}\right)$ (samples lacking all PNA staining). Representative distribution of Capza3 and PNA in sperm from the different treatments. 


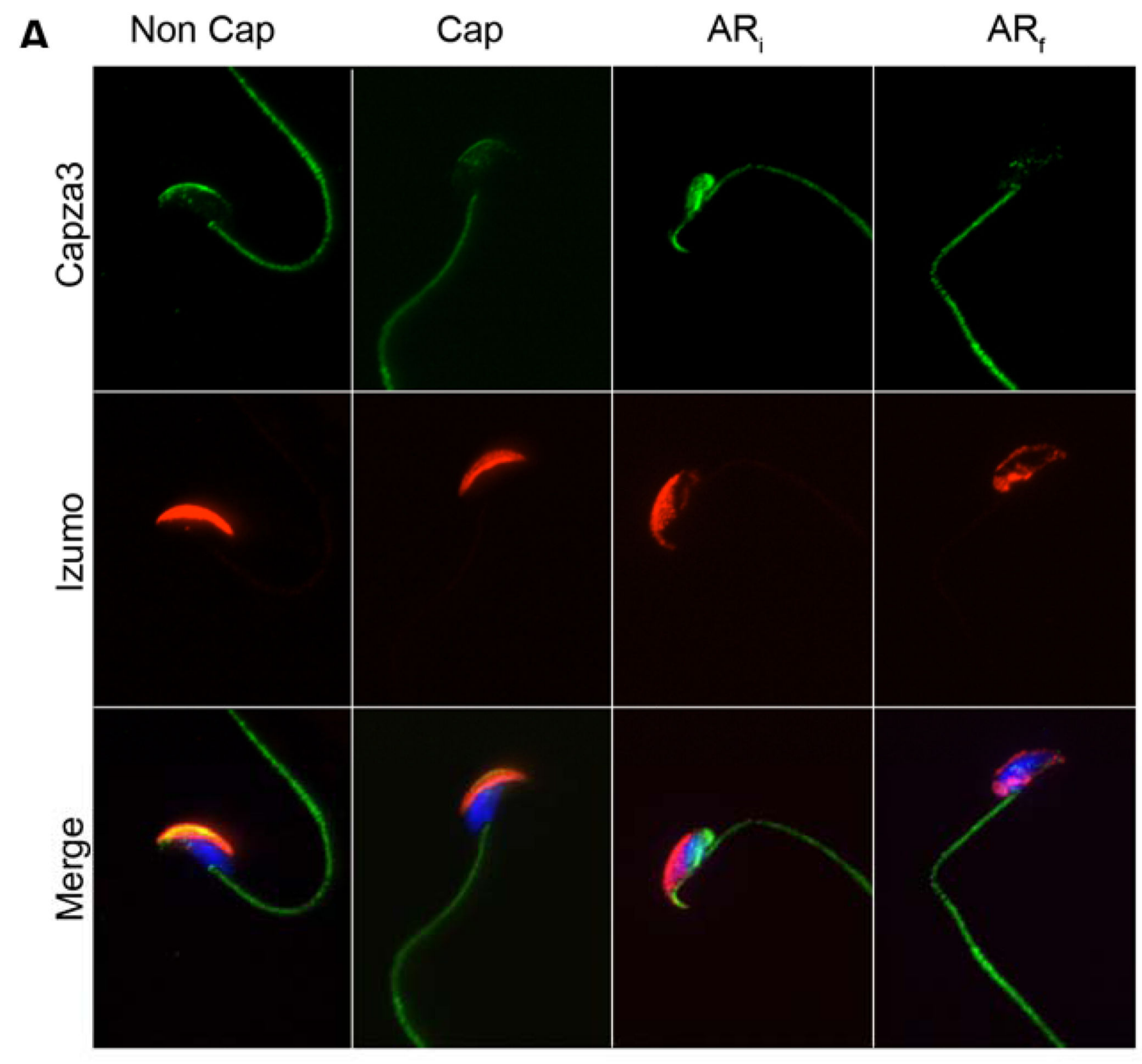

B

\section{Capza3 Localization (compaired to IZUMO)}

Fig. 2. Capza3 movement precedes that of Izumo

Sperm from the cauda of the epididymis from mature mice were obtained and incubated in media lacking (Non Cap) or containing (Cap) albumin and $\mathrm{NaCHO} 3$ for 90 minutes at $37^{\circ} \mathrm{C}$. A third group was incubated in capacitating media for 60 minutes and an additional 30 minutes after the addition of $\mathrm{Ca} 2+$ ionophore (AR). The samples were then mounted on drops on glass slides and fixed as indicated in materials and methods. After permeabilization the samples were stained for Capza3 using the GP-SH4 antibody and for Izumo using the OBF13 antibody. Fluorescent secondary antibodies were used in conjunction with DAPI as counterstain. The extent of the acrosome reaction was judged by the extent of Izumo 
relocalization and samples separated for quantification into initial acrosome reaction (ARi) and final acrosome reaction (ARf). Representative distribution of Capza3 and Izumo in sperm from the different treatments. 


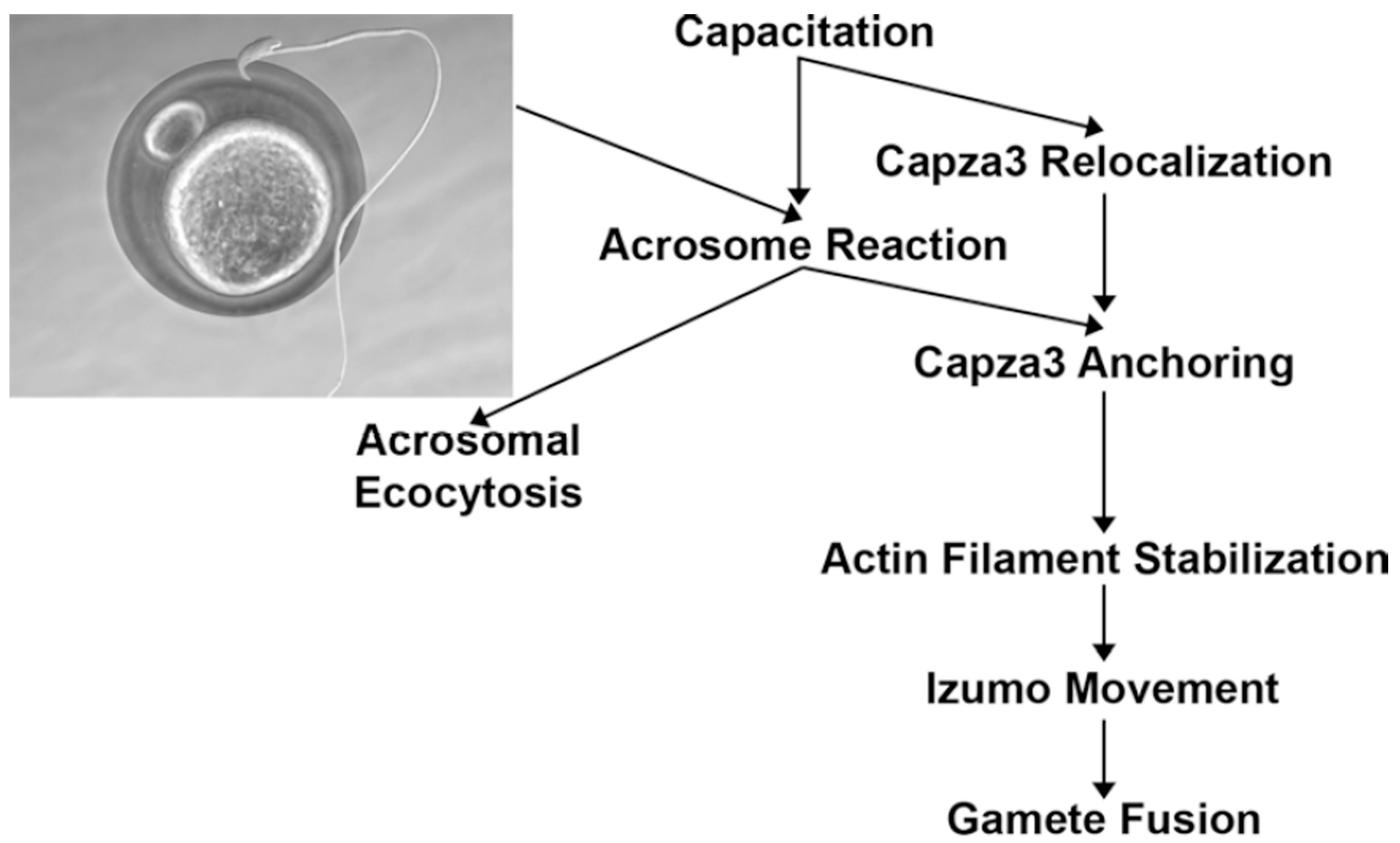

Fig. 3. Proposed model for Capza3 relocalization and activity In this proposed model capacitation leads to Capza3 relocalization from the anterior head of the sperm towards the posterior head. Upon acrosome reaction Capza3 anchors itself in the post-acrosomal compartment were is acts capping actin filaments stabilizing them. These stabilized actin filaments can then be used for active transport of sperm proteins required for sperm activity like the relocalization of Izumo necessary for the fusion of the gamete membranes. The retrograde displacement of Capza3 appears to be simultaneous but independent from the acrosomal exocytosis. 
Table 1

CAPZA3 localization varies in accordance to sperm status as judged by PNA staining

Numerical quantification from the experiment described in Fig. 1. The numbers represent the percent of sperm presenting a specific staining pattern for a given condition \pm s.d. 200 sperm were counted per condition per experiment. $\mathrm{n}=6$.

\begin{tabular}{|l|c|c|c|c|}
\hline & Non Cap & Cap & $\mathbf{A R}_{\mathbf{i}}$ & $\mathbf{A R}_{\mathbf{f}}$ \\
\hline Acrosome & $75 \pm 5$ & $4 \pm 1$ & $2 \pm 1$ & $1 \pm 1$ \\
\hline Diffuse & $5 \pm 2$ & $73 \pm 6$ & $2 \pm 1$ & $1 \pm 1$ \\
\hline Post-Acrosome & $18 \pm 3$ & $22 \pm 5$ & $95 \pm 2$ & $7 \pm 4$ \\
\hline Undetectable & $2 \pm 1$ & $1 \pm 1$ & $1 \pm 1$ & $91 \pm 6$ \\
\hline
\end{tabular}


Table 2

Capza3 localization varies in accordance to sperm status as judged by the localization of Izumo

Numerical quantification from the experiment described in Fig. 2. The numbers represent the percent of sperm presenting a specific staining pattern for a given condition \pm s.d. 200 sperm were counted per condition per experiment. $\mathrm{n}=6$.

\begin{tabular}{|l|c|c|c|c|}
\hline & Non Cap & Cap & $\mathbf{A R}_{\mathbf{i}}$ & $\mathbf{A R}_{\mathbf{f}}$ \\
\hline Acrosome & $76 \pm 5$ & $5 \pm 2$ & $1 \pm 1$ & $1 \pm 1$ \\
\hline Diffuse & $4 \pm 2$ & $72 \pm 7$ & $1 \pm 1$ & $1 \pm 1$ \\
\hline Post-Acrosome & $18 \pm 5$ & $21 \pm 5$ & $95 \pm 1$ & $7 \pm 3$ \\
\hline Undetectable & $2 \pm 1$ & $2 \pm 1$ & $2 \pm 1$ & $92 \pm 3$ \\
\hline
\end{tabular}


Table 3

\section{CAPZA3 localization in sperm treated with latrunculin A}

Cauda Epididymal sperm from mature mice were incubated in media lacking (Non Cap) or containing (Cap) albumin and $\mathrm{NaCHO}_{3}$ for 90 minutes at $37^{\circ} \mathrm{C}$. A third group was incubated in capacitating media for 60 minutes and an additional 30 minutes after the addition of $\mathrm{Ca}^{2+}$ ionophore (AR). All samples were treated with $25 \mu \mathrm{M}$ of the actin polymerization inhibitor latrunculin $\mathrm{A}$. The samples were then mounted on drops on glass slides and fixed as indicated in materials and methods. After permeabilization the samples were stained for CAPZA3 using the GP-SH4 antibody. Fluorescent secondary antibody was used in conjunction with fluorescent PNA and DAPI as counterstains. The extent of the acrosome reaction was judged by the extent of loss of PNA staining and samples separated for quantification into initial acrosome reaction $\left(\mathrm{AR}_{\mathrm{i}}\right)(\mathrm{samples}$ retaining partial PNA staining) and final acrosome reaction $\left(\mathrm{AR}_{\mathrm{f}}\right)$ (samples lacking all PNA staining). The numbers represent the percent of sperm presenting a specific staining pattern for a given condition \pm s.d. 200 sperm were counted per condition per experiment. $n=3$.

\begin{tabular}{|l|c|c|c|c|}
\hline & Non Cap & Cap & $\mathbf{A R}_{\mathbf{i}}$ & $\mathbf{A R}_{\mathbf{f}}$ \\
\hline Acrosome & $76 \pm 4$ & $4 \pm 2$ & $2 \pm 1$ & $1 \pm 1$ \\
\hline Diffuse & $4 \pm 1$ & $74 \pm 3$ & $1 \pm 1$ & $2 \pm 1$ \\
\hline Post-Acrosome & $18 \pm 4$ & $20 \pm 2$ & $96 \pm 2$ & $6 \pm 6$ \\
\hline Undetectable & $2 \pm 1$ & $2 \pm 1$ & $1 \pm 1$ & $92 \pm 6$ \\
\hline
\end{tabular}


Table 4

Capza3 localization varies in Tssk6 null sperm similarly to the changes observed in WT sperm (status judged by PNA staining)

Sperm from the cauda of the epididymis from mature Tssk6 null mice were obtained and incubated in media lacking (Non Cap) or containing (Cap) albumin and $\mathrm{NaCHO}_{3}$ for 90 minutes at $37^{\circ} \mathrm{C}$. A third group was incubated in capacitating media for 60 minutes and an additional 30 minutes after the addition of $\mathrm{Ca}^{2+}$ ionophore (AR). The samples were then mounted on drops on glass slides and fixed as indicated in materials and methods. After permeabilization the samples were stained for Capza3 using the GP-SH4 antibody. Fluorescent secondary antibody was used in conjunction with fluorescent PNA and DAPI as counterstains. The extent of the acrosome reaction was judged by the extent of loss of PNA staining and samples separated for quantification into initial acrosome reaction $\left(\mathrm{AR}_{\mathrm{i}}\right)$ (samples retaining partial PNA staining) and final acrosome reaction $\left(\mathrm{AR}_{\mathrm{f}}\right)$ (samples lacking all PNA staining). Numerical quantification from the experiment. The numbers represent the percent of sperm presenting a specific staining pattern for a given condition \pm s.d. 200 sperm were counted per condition per experiment. $n=3$.

\begin{tabular}{|l|c|c|c|c|}
\hline & Non Cap & Cap & $\mathbf{A R}_{\mathbf{i}}$ & $\mathbf{A R}_{\mathbf{f}}$ \\
\hline Acrosome & $78 \pm 3$ & $3 \pm 1$ & $1 \pm 1$ & $1 \pm 1$ \\
\hline Diffuse & $3 \pm 1$ & $72 \pm 1$ & $1 \pm 1$ & $1 \pm 1$ \\
\hline Post-Acrosome & $18 \pm 3$ & $23 \pm 2$ & $96 \pm 2$ & $5 \pm 6$ \\
\hline Undetectable & $2 \pm 1$ & $2 \pm 1$ & $1 \pm 1$ & $94 \pm 6$ \\
\hline
\end{tabular}

